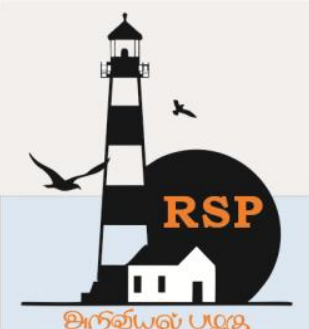

INTERNATIONAL RESEARCH JOURNAL ON ADVANCED SCIENCE HUB

RSP SCIENCE HUB

(The Hub of Research Ideas)

Available online at www.rspsciencehub.com

Special Issue of Second International Conference on Innovation in Engineering Sciences (ICIES2021)

\title{
Biological activity of green synthesized silver nanoparticles and different plant extracts of Solanum khasianum Clarke
}

Chirumamilla Pavani ${ }^{1}$, Taduri Shasthree ${ }^{2}$

${ }^{1}$ Research Scholar, Dept. of Biotechnology, Kakatiya University, Warangal, Telangana state, India.

${ }^{2}$ Assisstant Professor, Dept. of Biotechnology, Kakatiya University, Warangal, Telangana state, India. shastritaduri@gmail.com ${ }^{1}$, tadurishasthree@kakatiya.ac.in ${ }^{2}$

\begin{abstract}
Solanum khasianum Clarke. (Solanaceae), an important medicinal plant used to treat several diseases. Leaf, root, fruit and bark extracts of $S$. khasianum and the green synthesized silver nanoparticles were assayed for its antibacterial activity against gram positive and gram negative bacteria, using agar well diffusion method. Among all the solvent extracts tested, methanolic extracts were found to possess elevated activity. The optimal antibacterial activity is exhibited by silver nanoparticles against Pseudomonas flourescens with a maximal zone of inhibition (22mm). In the present study, the efficacy of green synthesized silver nanoparticles over the different plant extracts of $S$. khasianum against different bacterial strains was reported. This investigation discloses the potentiality of using silver nanoparticles as an antibacterial agent.
\end{abstract}

Keywords: Green synthesized silver nanoparticles, antimicrobial, Solanum khasianum, Methanolic extract

\section{Introduction}

There has been a great prevalence of microbial infections in humans due to the evolution of resistance towards wide range of antibiotics employed for the treatment in the recent years. The increase in the population, growing needs, poor sanitation and continuous exposure to same type of antibiotics and drugs has led to the development of resistance towards the drugs. Plants serve as a best alternative source for the synthetic drugs. Since ancient times, several medical traditions have been developed and followed by different civilizations. The evidence of usage of plants for the treatment of several diseases has been dated 60,000 years ago. Since then, nearly $60 \%$ of the world's population had been using plant parts as an alternative medicine [2]. India has a great treasury of medicinal plants. The usage of these medicinal plants was mentioned in several traditional systems in India like Ayurveda, Unani and Siddha.
Among which, ayurvedic system of traditional medicine was followed by $70 \%$ of the rural population of India [10]. Ayurvedic system of traditional medicine was developed based on the writings in the Veda's [1]. Charaka Samhita and Sushruta Samhita are two main compilations basically describing the utilization of medicinal plants in ayurvedic medicine and science of surgery. These traditional medical systems describe the use of crude plant extracts/ plant parts as the therapeutic agents [12]. Knowingly and unknowingly, most of the tribal hamlets depend on these herbal products for their health care. The scientific evidence of these traditional medicine has attracted the world to focus on these medicinal plants. Easy availability, no side effects and cost effectiveness are some of the factors for the rationalization of these plant-based medicines. The medicinal plants possess several phytochemicals, which impart antimicrobial properties. The 
antimicrobial property of the plants is mainly dependent on the amount and the type of phytoconstituents like steroids, flavonoids, tannins and saponins. These phytochemicals are said to be nonnutritive chemicals [9]. Hence, they serve as the reliable supply for the synthesis of many therapeutic drugs worldwide. Therefore, it is very significant to identify the plants with antimicrobial compounds. So far, several medicinal plants were reported to possess antimicrobial activity. Solanaceae is one such family with different biological activities. S. khasianum, belonging to the family Solanaceae is known for its varied medicinal properties [4]. Aforesaid kind of investigations has increased drastically during recent years, signifying the necessity and importance of plant-based antimicrobial compounds. Even though they possess the antimicrobial properties, further evaluation is necessary to study the toxicity of these drugs on humans [14]. The present investigation was reported for the first time and performed to evaluate the antimicrobial properties of different plant parts and green synthesized silver nanoparticles of Solanum khasianumby the Agar Diffusion method. This activity was performed using four different strains of bacteria including both gram-negative and gram-positive bacteria. These include the strains Escherichia coli, Pseudomonas fluorescens, Bacillus sphaericus and Proteus vulgaris.

\section{Materials and Methods}

\subsection{Collection and preparation of plant material} Different plant parts of Solanum khasianum like leaf, root, fruit and bark were collected, washed and shade dried. The completely dried plant material was finely chopped and ground into coarse powder. $5 \mathrm{~g}$ of each plant powder was added separately and dissolved in $50 \mathrm{ml}$ of different solvent systems like methanol, butanol, chloroform, acetonitrile and water. The plant extracts were obtained by the cold maceration method by incubating them in a rotary orbital shaker at $20^{\circ} \mathrm{C}$ for 2 days. The resultant extracts were filtered using Whatman filter paper and the samples were dried by rotary evaporator. The dried plant extracts were collected in sterile Eppendorf tubes and stored at $4^{\circ} \mathrm{C}$ for the evaluation of antimicrobial activity. The resultant plant material was dissolved in DMSO for assay.

\subsection{Green synthesis of silver nanoparticles}

The silver nanoparticles were synthesized from aqueous leaf extracts of S.khasianum. to which $1 \mathrm{mM} \mathrm{AgNO}_{3}$ was added, incubated till color change (green color to reddish brown color) and formation of silver nanoparticles was confirmed spectrophotometrically with a peak range of 400$500 \mathrm{~nm}$. The resultant solution is centrifuged, washed several times and air dried and preserved in the sterile Eppendorf tubes until further use.

\subsection{Inoculum development}

A loopful of pure cultures of Escherichia coli, Pseudomonas flourescens, Bacillus sphaericusand Proteus vulgaris were inoculated into $100 \mathrm{ml}$ of sterile nutrient broth and incubated at $28^{\circ} \mathrm{C}$ for $24 \mathrm{hrs}$ to obtain the inoculum. The $24 \mathrm{hrs}$ old cultures were used for the study of antimicrobial activity. The antimicrobial activity of Solanum khasianum was determined by the agar well diffusion method against some clinically significant gram positive and gram negative microbes. LB (Luria Bertani) agar medium was prepared, sterilized and poured into clean, sterile petridishes at a rate of $20 \mathrm{ml} /$ dish under aseptic conditions of laminar air flow and were allowed to solidify [13]. $200 \mu \mathrm{l}$ of inoculum was uniformly spread plated onto the solidified LB medium with the help of sterile L-shaped bent glass spreader. $6 \mathrm{~mm}$ wells with uniform spacing was created with $1 \mathrm{ml}$ sterile pipette tips. Different plant extracts like leaf, fruit, root, bark and green synthesized silver nanoparticles at a concentration of $20 \mu \mathrm{g} / \mathrm{ml}$, $30 \mu \mathrm{g} / \mathrm{ml}, 40 \mu \mathrm{g} / \mathrm{ml}$ and $50 \mu \mathrm{g} / \mathrm{ml}$ were loaded into each well $10 \mu \mathrm{l}$ streptomycin antibiotic as a positive control in the middle well. These plates were incubated at $37^{\circ} \mathrm{C}$ for $24 \mathrm{hrs}$ and were observed for zone of inhibition around each well and measured. Each experiment was conducted thrice.

\section{Results and discussion}

The antimicrobial screening of different plant extracts and green synthesized silver nanoparticles of Solanum khasianum revealed the presence of antimicrobial activity. Among the different solvent systems used for evaluation, methanolic plant extracts exhibited an optimal zone of inhibition than the other solvents like butanol, chloroform, acetonitrile and water. All the plant extracts showed the antimicrobial activity, but the intensity of inhibition varied among the bacterial strain 


\section{www.rspsciencehub.com}

used, type of the plant extract, solvent system and the concentration of the sample tested. The methanolic leaf extracts of Solanum khasianum revealed the high antimicrobial activity against $E$. coli than the other strains tested. As compared to the other solvent extracts, methanolic extract was found to be efficient. As the concentration of plant extract increased, the zone of inhibition has also increased notably (Fig. 1). Subsequently high inhibition activity was exhibited against P.fluorescens, followed by B. sphaericus. Whereas the leaf methanolic extracts showed less degree of inhibition zones against P.vulgaris in comparison with the other bacterial strains tested.

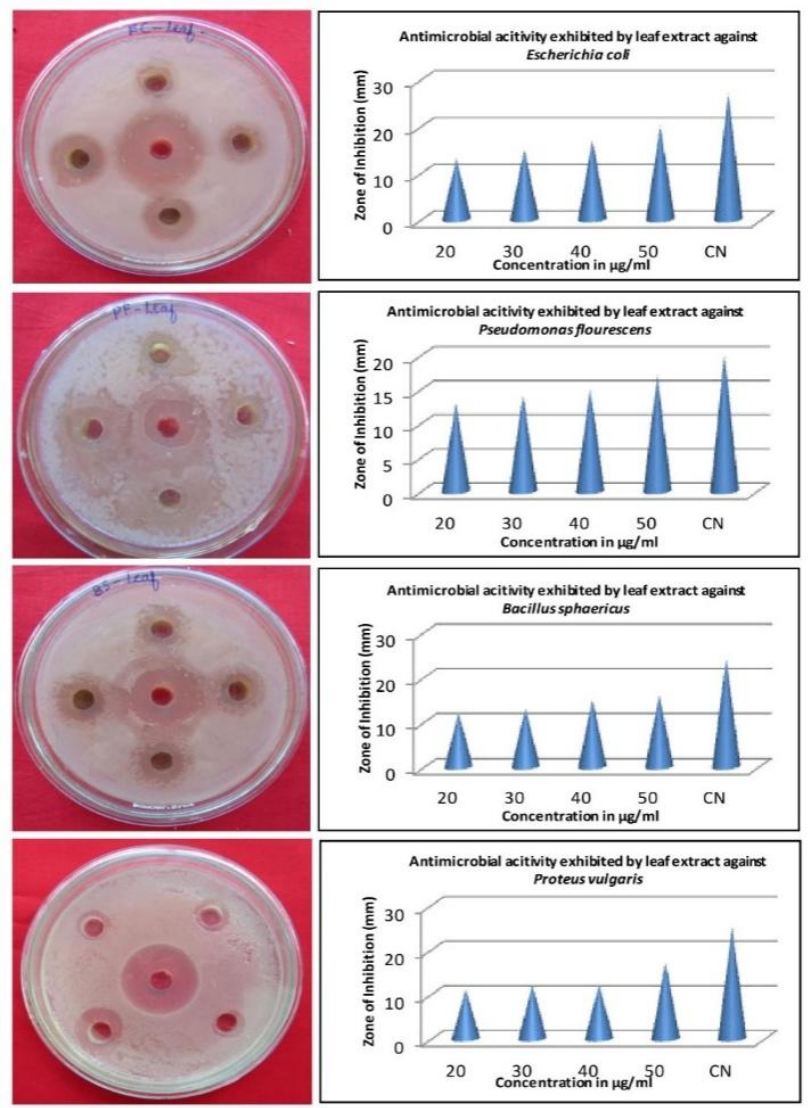

Fig.1. Antibacterial activity of methanolic leaf extracts of Solanum khasianum Clarke. Inhibition zones exhibited by leaf methanolic extract at different concentrations- (a) Escherichia coli, (b) Pseudomonas fluorescens, (c) Bacillus sphaericus, (d) Proteus vulgaris

The root methanolic extracts revealed the high antimicrobial activity with high extent of inhibition zones against P.fluorescens in comparison with the other bacterial strains evaluated (Fig. 2). In the root extracts also, the high antimicrobial activity is shown by the methanolic extracts than the other solvents. Subsequent high antimicrobial activity was
Volume 03 Issue 04S April 2021

expressed against $E$. coli, whereas the antimicrobial activity was found to be low and was almost similar against $B$. sphaericusand P.vulgaris.
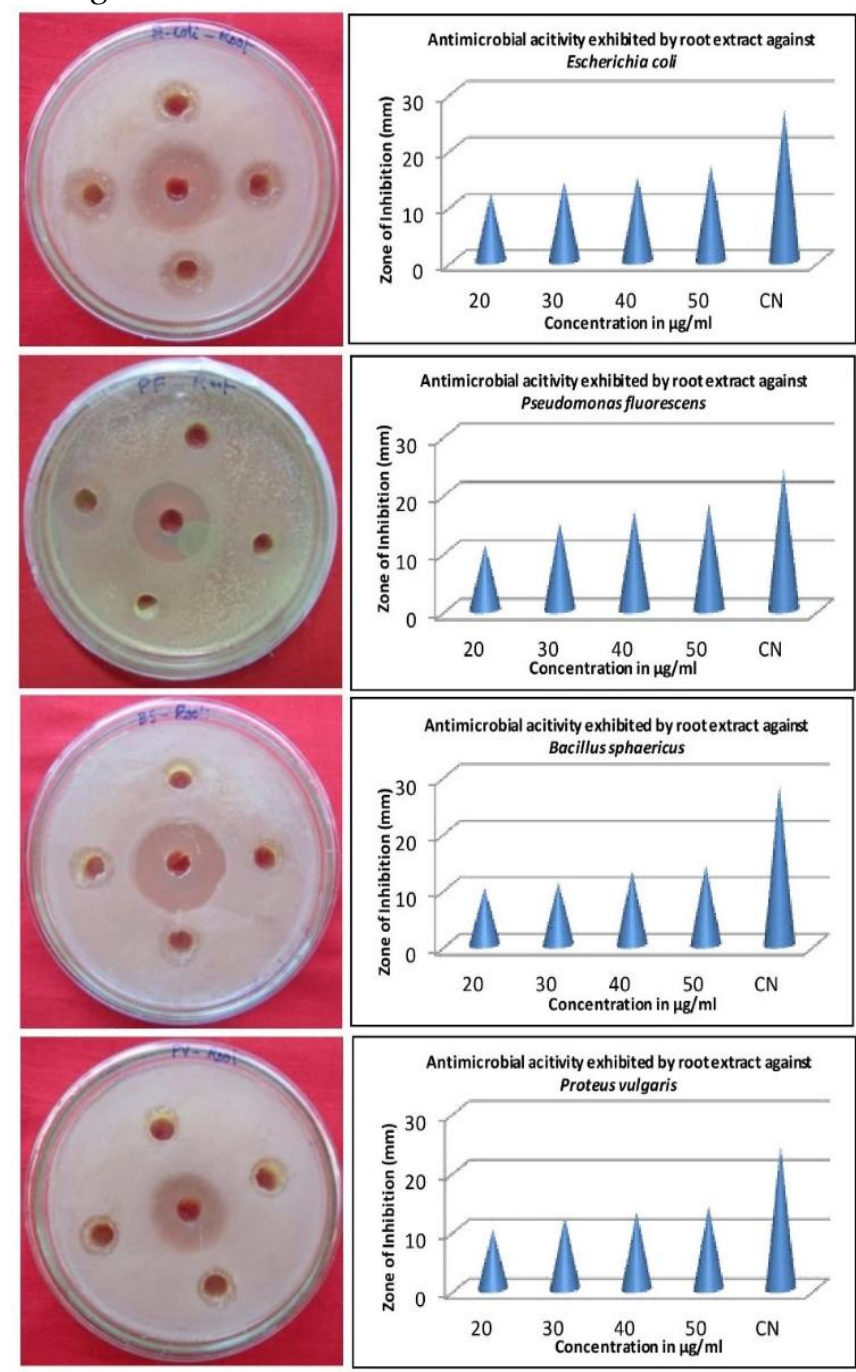

Fig.2. Antibacterial activity of methanolic root extracts of Solanum khasianum Clarke. Inhibition zones exhibited by root methanolic extract at different concentrations- (a) Escherichia coli, (b) Pseudomonas fluorescens, (c) Bacillus sphaericus, (d) Proteus vulgaris

The fruit extracts of Solanum khasianum also showed the antimicrobial activity against all the tested bacterial strains, where the methanolic extracts found to be efficient than other solvent extracts. The maximum antimicrobial activity of fruit methanolic extract was also exhibited against P.fluorescens than the other bacterial strains tested (Fig. 3). There observed the increase in the zone of inhibitions with the increase in the concentration of the plant extract. Subsequent maximum antimicrobial activity with moderate zone of inhibitions were shown against E. coli, followed by P.vulgaris and B. sphaericus. 
www.rspsciencehub.com

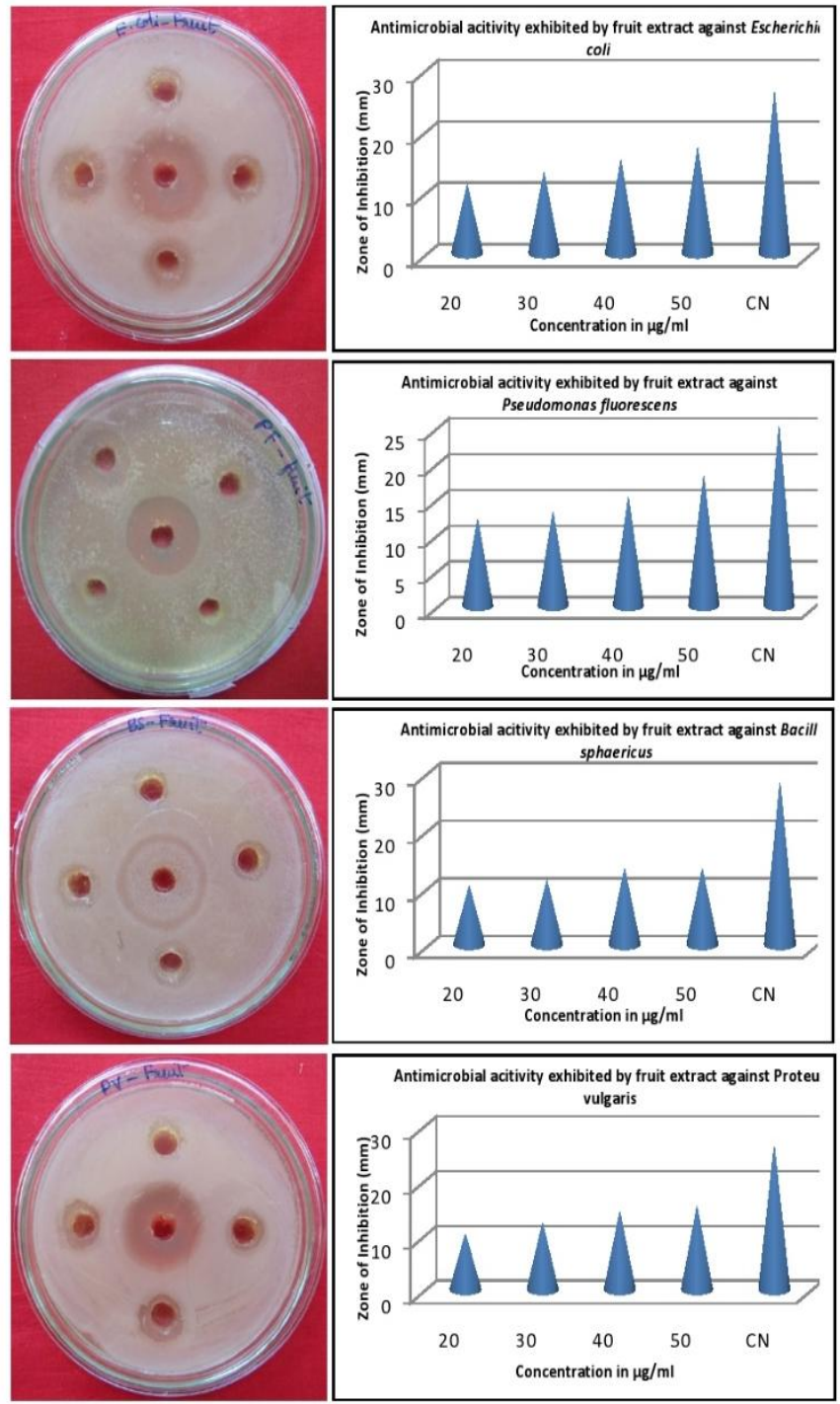

Fig.3. Antibacterial activity of methanolic fruit extracts of Solanum khasianum Clarke. Inhibition zones exhibited by fruit methanolic extract at different concentrations- (a) Escherichia coli, (b) Pseudomonas fluorescens, (c) Bacillus sphaericus, (d) Proteus vulgaris

The bark methanolic extracts of Solanum khasianum also showed the maximal zone of inhibition against P.fluorescens, in contrast to other bacterial strains evaluated (Fig. 4). Methanolic extracts showed sensitivity against all the bacteria tested than the other solvent extracts. Subsequent optimal inhibition zones were exhibited against E. coli and P.vulgaris. The lowest concentration $(20 \mu \mathrm{g} / \mathrm{ml})$ of bark extract did not showed any antimicrobial activity against $B$. sphaericus, whereas the increase in the concentration of the sample exhibited the inhibition zones.
Volume 03 Issue 04S April 2021
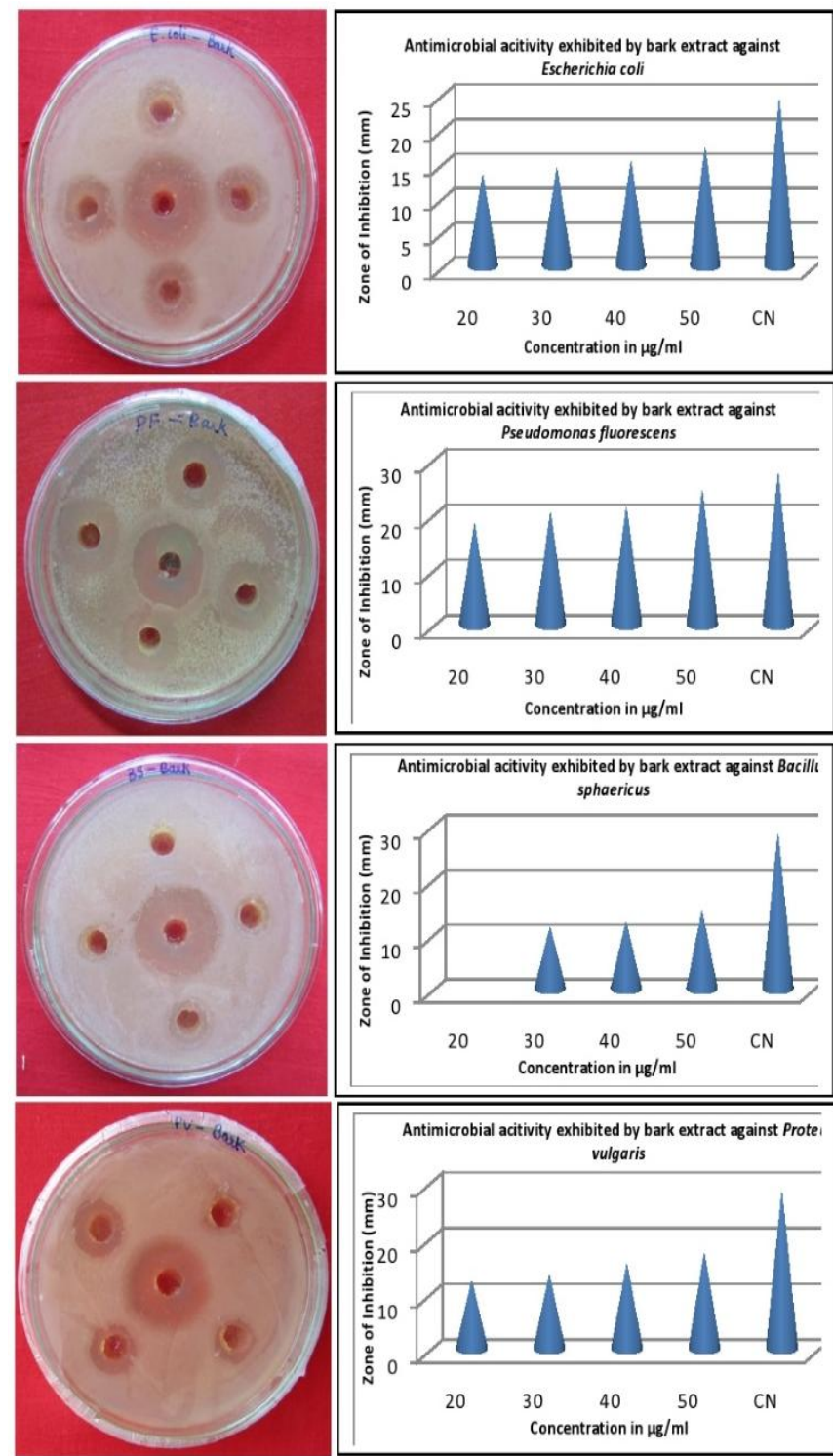

Fig.4. Antibacterial activity of methanolic bark extracts of Solanum khasianum Clarke. Inhibition zones exhibited by bark methanolic extract at different concentrations- (a) Escherichia coli, (b) Pseudomonas fluorescens, (c) Bacillus sphaericus, (d) Proteus vulgaris

The green synthesized silver nanoparticles of S.khasianum revealed the presence of high microbial activity than all the plant extracts tested. The high antimicrobial activity of silver nanoparticles is exhibited against P.fluorescens in comparison to other bacterial strains tested (Fig. 5 ). increase in the concentration of the sample resulted in the high antimicrobial activity. Subsequent high antibacterial activity is exhibited against P.vulgaris, E. coli and B. sphaericus. 

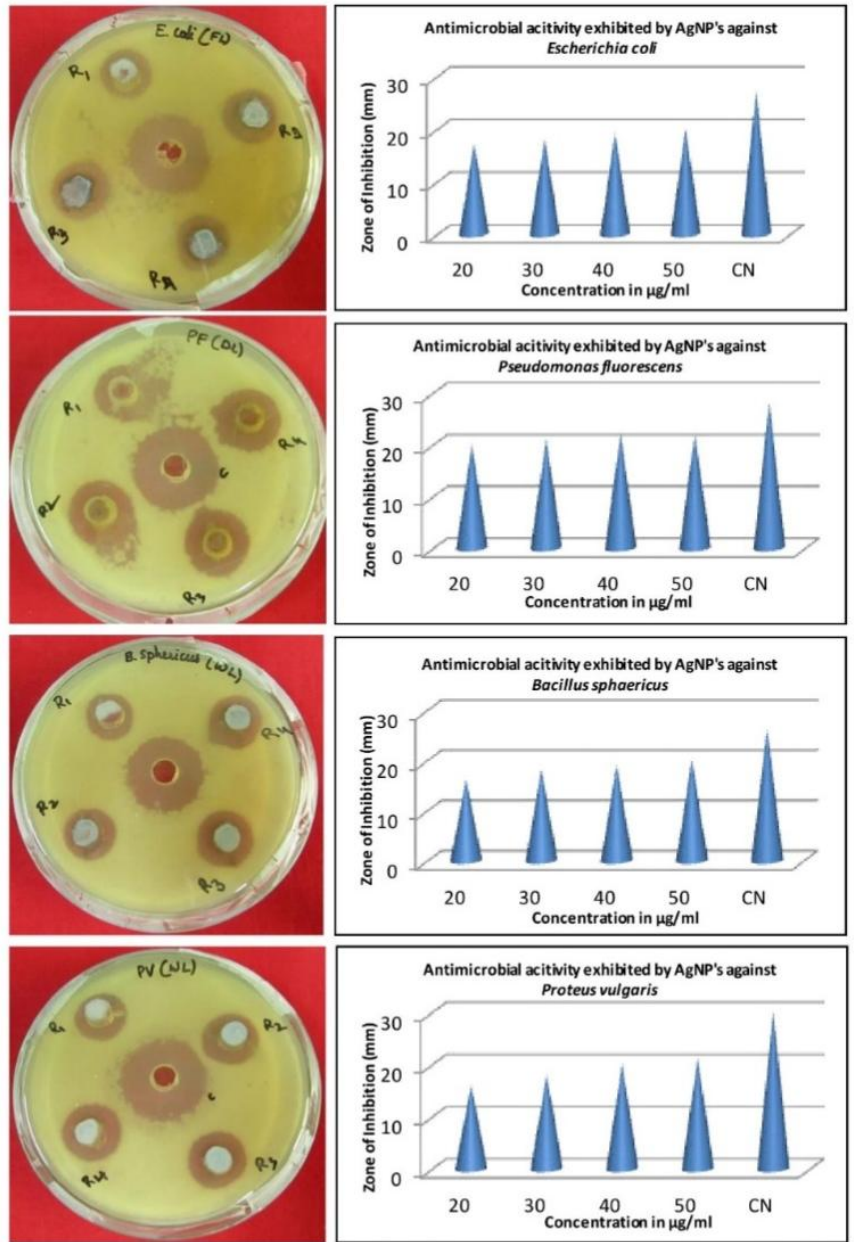

Fig.5. Antibacterial activity of green synthesized silver nano particles of Solanum khasianum Clarke. Inhibition zones exhibited by leaf methanolic extract at different concentrations- (a) Escherichia coli, (b) Pseudomonas fluorescens, sphaericus, (d) Proteus vulgaris

(c) Bacillus

Among all the solvent extracts tested, high antimicrobial activity with high extent of inhibition zones was exhibited by methanolic extracts only. Similar results of high antibacterial activity were expressed by the methanolic extracts of Solanum aculeastrum than the other extracts, against both gram positive and gram negative bacteria [7]. As the concentration of the plant extracts increase, the zones of inhibition also tend to increase [3]. A similar result of high antimicrobial activity of green synthesized silver nanoparticles was reported by several scientists [5, 6, 8, 11, and 15].

\section{Conclusions}

The present investigation revealed the significant efficacy of green synthesized silver nanoparticles and different methanolic plant extracts of Solanum khasianumagainst gram positive and gram negative bacteria. These findings were also helpful to validate the claims on usage of this medicinal plant to treat several ailments and to develop new drugs.

\section{Acknowledgement}

The authors duly acknowledge the Department of Biotechnology, Kakatiya University, and Warangal for providing all the facilities for carrying out the research.

\section{References}

[1] Adhikari, P. P., \& Paul, S. B. (2018). History of Indian traditional medicine: A medical inheritance. HISTORY, 11(1).

[2] Ballabh, B., \&Chaurasia, O. P. (2007). Traditional medicinal plants of cold desert Ladakh - used in treatment of cold, cough and fever. Journal of ethnopharmacology, 112(2), 341-349.

[3] Britto, S. J., \&Senthilkumar, S. (2001). Antibacterial activity of Solanum incanum L. leaf extracts. Asian Journal of Microbiology, Biotechnology \& Environmental Sciences, 3(1), 65-66.

[4] Chirumamilla, P., Gopu, C., Jogam, P., \&Taduri, S. (2021). Highly efficient rapid micropropagation and assessment of genetic fidelity of regenerants by ISSR and SCoT markers of Solanum khasianum Clarke. Plant Cell, Tissue and Organ Culture (PCTOC), 144(2), 397-407.

[5] Das, S., \& Chakraborty, T. (2018). A review on green synthesis of silver nanoparticle and zinc oxide nanoparticle from different plants extract and their antibacterial activity against multi-drug resistant bacteria. Journal of Innovations in Pharmaceutical and Biological Sciences, 5, 63-73.

[6] Kagithoju, S., Godishala, V., \& Nanna, R. S. (2015). Eco-friendly and green synthesis of silver nanoparticles using leaf extract of Strychnospotatorum Linn. F. and their bactericidal activities. 3 Biotech, 5(5), 709714.

[7] Koduru, S., Grierson, D. S., \&Afolayan, A. J. (2006). Antimicrobial Activity of Solanum aculeastrum. Pharmaceutical biology, 44(4), 283-286.

[8] Krithiga, N., Rajalakshmi, A., \&Jayachitra, A. (2015). Green synthesis of silver nanoparticles using leaf extracts of Clitoriaternatea and 
Solanum nigrum and study of its antibacterial effect against common nosocomial pathogens. Journal of Nanoscience, 2015.

[9] Murugan, T., Wins, J. A., \&Murugan, M. (2013). Antimicrobial activity and phytochemical constituents of leaf extracts of Cassia auriculata. Indian journal of pharmaceutical sciences, 75(1), 122.

[10] Pandey, M. M., Rastogi, S., \& Rawat, A. K. S. (2013). Indian traditional ayurvedic system of medicine and nutritional supplementation. Evidence-Based

Complementary and Alternative Medicine, 2013.

[11]Phirange, A. S., \& Sabharwal, S. G. (2019). Green synthesis of silver nanoparticles using Fagopyrum esculentum starch: antifungal, antibacterial activity and its cytotoxicity.

[12] Ravishankar, B., \& Shukla, V. J. (2007). Indian systems of medicine: a brief profile. African Journal of Traditional, Complementary and Alternative Medicines, 4(3), 319-337.

[13] Sezonov, G., Joseleau-Petit, D., \&d'Ari, R. (2007). Escherichia coli physiology in LuriaBertani broth. Journal of bacteriology, 189(23), 8746-8749.

[14] Silva, N. C. C., \& Fernandes Júnior, A. J. J. O. V. A. (2010). Biological properties of medicinal plants: a review of their antimicrobial activity. Journal of venomous Animals and Toxins including tropical diseases, 16(3), 402-413.

[15] Swamy, M. K., Akhtar, M. S., Mohanty, S. K., \&Sinniah, U. R. (2015). Synthesis and characterization of silver nanoparticles using fruit extract of Momordica cymbalaria and assessment of their in vitro antimicrobial, antioxidant and cytotoxicity activities. Spectrochimica Acta Part A: Molecular and Biomolecular Spectroscopy, 151, 939-944. 